\title{
$\mathrm{Cl}$ i ni copat hol ogi c st udy of mixed adenoneur oendocri ne car ci nomas of hepat obi I i ary organs.
}

\begin{tabular}{|l|l|}
\hline 著者 & $\begin{array}{l}\text { Har ada Keni chi, Sat o Yasunor i, I keda Hi roko, } \\
\text { Nayl ee Hsu, I gar ashi Saya, Okamur a At sushi , } \\
\text { Nasuda Shi nj i, Nakanuma Yasuni }\end{array}$ \\
\hline $\begin{array}{l}\text { j our nal or } \\
\text { publ i cat i on t i tl e }\end{array}$ & $\begin{array}{l}\text { Vi r chows Ar chi v : an i nt er nat i onal j our nal of } \\
\text { pat hol ogy }\end{array}$ \\
\hline vol une & 460 \\
\hline number & 3 \\
\hline page r ange & $281-289$ \\
\hline year & 2012- 03-01 \\
\hline URL & ht t p: //hdl . handl e. net /2297/31405 \\
\hline
\end{tabular}




\section{Clinicopathologic study of mixed adenoneuroendocrine carcinomas of}

\section{hepatobiliary organs}

Kenichi Harada, M.D. ${ }^{1)}$, Yasunori Sato, M.D. ${ }^{1)}$ Hiroko Ikeda, M.D. ${ }^{2)}$, Hsu Maylee, M.D. ${ }^{1)}$, Saya Igarashi, M.D. ${ }^{1)}$, Atsushi Okamura, M.D. ${ }^{1)}$, , Shinji Masuda, M.D. ${ }^{3)}$, and Yasuni Nakanuma, M.D. ${ }^{1)}$

1) Department of Human Pathology, Kanazawa University Graduate School of Medicine, Kanazawa, Japan

2) Division of Pathology, Kanazawa University Hospital, Kanazawa, Japan

3) Department of Pathology, Kouseiren Takaoka Hospital, Takaoka, Japan

Short running title: biliary mixed adenoneuroendocrine carcinoma

Key Words: neuroendocrine neoplasm, cholangiocarcinoma, mixed adenoneuroendocrine carcinoma, somatostatin analogue

Address correspondence to:

Kenichi Harada, M.D.

Department of Human Pathology

Kanazawa University Graduate School of Medicine

Kanazawa 920-8640, Japan

FAX: (0)76-234-4229 (Japan)

TEL: (0)76-265-2199 (Japan)

E-mail: kenichih@med.kanazawa-u.ac.jp 


\section{SUMMARY}

Backgrounds: Neuroendocrine neoplasms in hepatobiliary organs are very rare, but several cases of mixed adenoneuroendocrine carcinoma (MANEC) have been reported. In this study, we characterized the neuroendocrine component of biliary MANEC. Materials and methods: A total of 274 cases of biliary cancer including 17 intrahepatic cholangiocarcinomas (CCs), 15 hepatic hilar CCs without preceding hepatobiliary disease, 55 hepatic hilar CCs with hepatolithiasis, 49 gallbladder cancers, 53 extrahepatic CCs, and 85 hepatocellular carcinomas (HCC) were examined for an neuroendocrine component by immunohistochemistry with neuroendocrine markers (chromogranin A and synaptophysin). In the MANEC cases, in addition to a close histological examination, the proliferative activity and the expression of somatostatin receptor $2 \mathrm{~A}$ were also evaluated. Results: In addition to an ordinary adenocarcinoma, an neuroendocrine component occupying more than $30 \%$ of the entire tumor was also found in $4 \%$ (2/55 cases) of hepatic hilar cholangiocarcinomas with hepatolithiasis, $10 \%$ (5/49 cases) of gallbladder cancers, and $4 \%(2 / 53$ cases) of extrahepatic cholangiocarcinomas, but not in the intrahepatic cholangiocarcinomas, hilar cholangiocarcinomas without preceding hepatobiliary disease, and hepatocellular carcinomas. Two cases were positive for somatostatin receptor 2A. The adenocarcinoma components were predominately located at the surface of the tumors and the majority of stromal and vascular invasion and lymph node metastasis involved neuroendocrine components showing features of neuroendocrine tumor G2 or neuroendocrine carcinomas (NECs). NEC components showed higher proliferative activity on Ki67 immunostaining, compared to the adenocarcinoma components. Conclusion: Biliary MANECs are found in hepatic hilar cholangiocarcinomas with hepatolithiasis, gallbladder cancers, and extrahepatic cholangiocarcinomas and show a characteristic histology. Since the neuroendocrine component in biliary MANEC defines the prognosis, it is important to identify it and consider the indications for adjunctive therapy with somatostatin analogues. 


\section{INTRODUCTION}

Neuroendocrine neoplasms including carcinoid tumors are commonly found in several organs including the pancreas and gastrointestinal tract. The World Health Organization (WHO) classification (2000)[1] has been widely used to categorize neuroendocrine tumors (NETs) for all anatomical sites and NETs are histologically and biologically classed as well-differentiated neuroendocrine tumors, well-differentiated neuroendocrine carcinomas (low grade malignancy), poorly differentiated neuroendocrine carcinomas (high grade malignancy), and mixed exocrine-endocrine carcinomas [2,3]. The European Neuroendocrine Tumor Society (ENETS) has recently proposed two complementary classification tools - a grading classification and a site-specific staging system [4]. The recent WHO classification $(2010)[5,6]$, moreover, strengthens the appreciation of 3 concepts: tumor heterogeneity, tumor differentiation, and malignancy. According to the WHO classification (2010), neuroendocrine neoplasms in the digestive system including gallbladder and extrahepatic bile ducts are classed as NET G1 (carcinoid, mitotic count $<2$ per 10 high powder fields $[\mathrm{HPF}]$ and/or $\leq 2 \% \mathrm{Ki67}$ index), NET G2 (mitotic count 2-20 per $10 \mathrm{HPF}$ and/or 3-20\% Ki67 index), NET G3 (neuroendocrine carcinoma [NEC], mitotic count $>20$ per $10 \mathrm{HPF}$ and/or $>20 \%$ Ki67 index), and mixed adenoneuroendocrine carcinoma (MANEC). This classification reflects the prognosis of patients with neuroendocrine neoplasms as well as biologic potential and is based on general pathological findings such as tumor size, differentiation, mitotic index, perineural or vascular invasion, metastasis, and local invasion to muscular propria (gastrointestinal tracts) and adjacent organs $[2,3]$. Typical carcinoids showing benign behavior and atypical carcinoids showing malignant features are equated with NET G1 and NET G2, respectively. NEC includes small cell carcinoma and large cell neuroendocrine carcinoma (LCNEC) considered as homologous to the pulmonary counterpart $[2,3]$.

Neuroendocrine cells and tumors are characterized by the expression of markers such as 
chromogranin A and synaptophysin and the production of hormonal substances including serotonin, gastrin, and somatostatin. However, because some neuroendocrine neoplasms lack distinct or functional hormones, a functional classification is of little value. Recently, it was demonstrated that somatostatin analogues such as SOM230 and octreotide are the best therapeutic option for neuroendocrine neoplasms, because they reduce hormone-related symptoms and also have antitumor effects $[7,8]$. A neuroendocrine neoplasm demonstrated to possess the receptor for somatostatin (SSTR) is a good candidate for treatment with a somatostatin analogue. Therefore, the pathological differentiation and diagnosis of neuroendocrine neoplasms is important for chemotherapy after the resection of a tumor [7]. Tumors originating from the intrahepatic and extrahepatic biliary trees are mostly malignant carcinomas, in particular adenocarcinomas, irrespective of their etiology. Physiologically, a few neuroendocrine cells resembling enterochromaffin-like cells exist in the biliary tree, particularly in the large bile ducts and peribiliary glands of the hepatic hilus [9], but cases of neuroendocrine neoplasms in hepatobiliary organs are extremely rare. Carcinoids of the gallbladder and the extrahepatic biliary tract represent $0.2 \%$ and $0.01 \%$ of all carcinoids, respectively [1].

To date, several cases of hepatobiliary neuroendocrine neoplasms, mostly biliary adenocarcinomas accompanying an neuroendocrine component (MANEC), have been reported [10-14], but the neuroendocrine component in biliary MANEC is not well characterized. In this study, we surveyed neuroendocrine neoplasms in hepatobiliary tumors and characterized hepatobiliary MANEC. Our final aim was to assess the clinicopathological significance of neuroendocrine components in hepatobiliary MANEC including the prognosis after the surgical resection of tumors.

\section{MATERIALS and METHODS}




\section{Patients and tissue preparations}

A total of 274 cases of biliary cancer including 17 intrahepatic cholangiocarcinomas (CC), 15 hepatic hilar CCs without preceding hepatobiliary disease, 55 hepatic hilar CCs with hepatolithiasis, 49 gallbladder cancers, 53 extrahepatic CCs, and 85 hepatocellular carcinomas (HCCs) were examined in this study. All materials were surgically resected hepatobiliary specimens retrieved from the surgical files of our laboratories and affiliated hospitals. These tissue specimens containing tumorous lesions were immediately fixed in $10 \%$ neutral-buffered formalin and embedded in paraffin. Several $4 \mu \mathrm{m}$-thick sections were prepared from each paraffin-embedded block and either routinely stained for histologic evaluation or processed for immunohistochemical analysis.

\section{Immunohistochemistry}

Using representative cancerous sections from each case and also cases involving neuroendocrine neoplasms, all sections including lymph nodes were prepared for pathological diagnosis, and the immunohistochemical staining of neuroendocrine markers (chromogranin A and synaptophysin) was performed for surveying the presence of neuroendocrine neoplasms. Moreover, in cases involving neuroendocrine neoplasms, a cell proliferative marker (Ki67) and SSTR type 2A (SSTR2A) were also immunostained to examine the cell kinetics as a marker of malignancy and the indications for treatment with somatostatin analogues.

Deparaffinized and rehydrated sections were pretreated for antigen retrieval prior to staining (Table 1). Following endogenous peroxidase blocking and incubation in normal goat serum (1:10; Vector Lab, Burlingame, CA) for $20 \mathrm{~min}$, these sections were incubated at $4{ }^{\circ} \mathrm{C}$ overnight with primary antibodies (Table 1), and then at room temperature for 1 hour with goat anti-mouse or anti-rabbit immunoglobulins conjugated to a peroxidase-labeled dextran polymer (Envision, Dako Japan). After a benzidine reaction, sections were weakly counterstained with hematoxylin. As a 
negative control, nonimmune serum was used for the primary antibody. This procedure consistently resulted in no staining.

\section{Examination of hepatobiliary neuroendocrine neoplasms}

Chromogranin A- and/or synaptophysin-positive cells were evaluated as neuroendocrine cells and a neuroendocrine neoplasm was basically defined as a well- to poorly differentiated tumor composed of cells with features similar to those of the normal gut endocrine cell, showing the diffuse and distinct staining for chromogranin A and/or synaptophysin [5]. The grading for neuroendocrine neoplasms (NET G1, G2, or G3 [NEC]) was performed on the basis of morphological criteria and the assessment of the proliferative fraction according to the ENETS scheme [4]: we established a Ki67 labeling index as a percentage of 2000 cells counted in the area of strongest nuclear labeling and mitotic count per 10 high powder fields (HPFs) by evaluating at least 50 HFPs. In MANEC cases, at least $30 \%$ of the main lesion excluding any broad invasive area had to be made up of either component for this definition to apply [5] and the following pathological features were also examined; tumor size, gross classification (mass forming, periductal infiltrating, or intraductal growth), depth of invasion, lymphatic, vascular, and perineural invasion (present or absent, and if present, its histology), and lymph node metastasis (present or absent, and if present, its histology).

\section{RESULTS}

\section{Staining pattern of chromogranin A and synaptophysin}

Hepatobiliary tumors merely contain cells positive for the neuroendocrine marker chromogranin A or synaptophysin. However, in some biliary tumors, the positive cells were scattered and sometimes clustered within tumors and extended within the biliary epithelium of adjacent non-neoplastic bile ducts (Fig.1). Some neuroendocrine cells resembling enterochromaffin-like cells 
morphologically were also found (Fig.1). The scattering and/or clustering of these neuroendocrine cells was found in 12 of 55 hepatic hilar CCs with hepatolithiasis, 19 of 49 gallbladder cancers, and 13 of 53 extrahepatic CCs, but not in HCCs, intrahepatic CCs, or hepatic hilar CCs without preceding hepatobiliary disease (Table 2).

\section{Clinicopathological features of the neuroendocrine component in hepatobiliary MANEC}

No cases of $\mathrm{HCC}$, intrahepatic $\mathrm{CC}$, and hepatic hilar $\mathrm{CC}$ without preceding hepatobiliary disease included neuroendocrine components. In contrast, hepatic hilar CC with hepatolithiasis, gallbladder cancer, and extrahepatic CC accompanied neuroendocrine components in addition to ordinary adenocarcinoma in $4 \%, 10 \%$, and $4 \%$ of cases, respectively (Table 2 ). A summary of a total of 9 cases of biliary MANEC found in this study is shown in Table 3. As shown in Figs.2-4, representative findings of these MANEC cases showed that the adenocarcinoma component was located at the surface of tumors and the majority of the stromal invasion including vascular invasion and lymph node metastasis involved neuroendocrine components. These components were NET G2 or NEC, the tumor cells of which had a round- or oval-shaped nucleus and "salt-and-pepper" pattern of nuclear chromatin, general characteristics of neuroendocrine cells. NET G1 was not found in any cases (Table 3). Cases of NEC showed morphological features of small cell carcinoma or large cell neuroendocrine carcinoma, broadly typical of lung cancer. In biliary MANEC, the components showing the deepest invasion were neuroendocrine neoplasms and vascular and perineural invasion also involved neuroendocrine components. Moreover, several other characteristics were evident as follows. The NEC (LCNEC) component in Case 1 had widespread necrosis. In Case 2 composed of an uniformly well-differentiated tubular adenocarcinoma, a neuroendocrine marker-positive tubular component was also found in an invasive area (Fig.5). Although the Ki67 index was less than $2 \%$, the NET in Case 2 was categorized as NET G2 according to the morphology and mitotic index. The Ki67 index in Case 3 was less than 20\%, but this case was regarded as NEC in consideration of the small cell 
carcinoma-like morphology with necrosis and mitotic index. The NEC component in Case 4 had the highest proliferative activity among the biliary MANEC cases examined in this study. The Ki67 index in Case 5 was less than $2 \%$, but this tumor was regarded as NET G2 based on morphology and the mitotic index (Fig.2). In Case 6, the NEC component (small cell carcinoma) had conspicuous necrosis (Fig.3) and the ordinary adenocarcinoma as well as NEC component also showed distinct stromal and vascular invasion. The NEC component (LCNEC) in Case 7 had widespread necrosis. Cases 8 and 9 were MANEC cases arising from the preceding hepatolithiasis and the NEC component (LCNEC) in Case 9 clearly had necrosis.

Immunohistochemistry revealed that Ki67-positive cells were scattered in the neuroendocrine component as well as ordinary adenocarcinoma, and in particular, many positive tumor cells were found in NEC (Fig.6). Quantitative evaluation also confirmed that the NEC component constantly showed high proliferative activity, compared with the adenocarcinoma component in each case (Fig.6). SSTR2A expression was found in the cytoplasm and membrane of tumor cells of the adenocarcinoma and neuroendocrine components. However, significant membranous expression [7] was restricted to the neuroendocrine component and 2 cases of biliary MANEC clearly expressed SSTR2A with a NEC histology (Fig.7 and Table 3).

\section{DISCUSSION}

Several cases of hepatobiliary neuroendocrine neoplasms including carcinoid tumors have been reported, but most involve hepatic carcinoids or biliary neuroendocrine neoplasms arising from or accompanying ordinary adenocarcinomas, mostly in patients with gallbladder cancer and extrahepatic CC [10-14]. One case of hepatic NET G1 (carcinoid tumor), but no pure biliary neuroendocrine neoplasms without ordinary $\mathrm{CC}$, has been registered in our laboratories and affiliated hospitals. In this study, we primarily surveyed the presence of neuroendocrine neoplasms 
in hepatobiliary tumors (CC and $\mathrm{HCC}$ ) using immunohistochemistry for chromogranin $\mathrm{A}$ and synaptophysin. CD56 (NCAM) is also used as a neuroendocrine marker, but biliary epithelial cells in intrahepatic small bile ducts, particularly bile ductules, and their tumors are positive for CD56 [15]. Therefore, CD56 is not suitable for the identification of neuroendocrine neoplasms in biliary tumors. Consequently, as for intrahepatic neuroendocrine neoplasms, no cases of $\mathrm{HCC}$ or intrahepatic CC accompanying neuroendocrine neoplasms were found in this study, though one case of hepatic carcinoid was registered in our files. This finding is very interesting when considering the tumorigenesis of intrahepatic neuroendocrine neoplasms such as hepatic carcinoid; intrahepatic neuroendocrine neoplasms are unlikely to originate from hepatocytes, cholangiocytes in intrahepatic small bile ducts, and their carcinomas (HCC and intrahepatic $\mathrm{CC}$ ). Therefore, an association between hepatic stem cells, that is, multipotential progenitor cells possessing the ability to differentiate into various cell types including neuroendocrine cells, and heterotopic neuroendocrine tissue possibly remains in the tumorigenesis of hepatic neuroendocrine neoplasms. In contrast, the proliferation of neuroendocrine cells and the presence of biliary neuroendocrine neoplasms accompanied by biliary adenocarcinoma were found in hepatic hilar CC with hepatolithiasis in addition to gallbladder cancer and extrahepatic CC. This finding is also of interest when considering the tumorigenesis of biliary neuroendocrine neoplasms and suggests that preceding chronic inflammation, particularly lithiasis-associated inflammation, and the accidental proliferation of neuroendocrine cells are closely associated with the histogenesis of biliary neuroendocrine neoplasms. The absence of cases of hepatic hilar CC without preceding hepatobiliary disease supports this speculation. As for the incidence, among biliary cancers, gallbladder cancers most often accompany neuroendocrine neoplasms in $10 \%(5 / 49)$ of cases. In this study, we surveyed cases of biliary cancer and collected MANEC cases from affiliated hospitals which specialize in hepatobiliary diseases. Therefore, the possibility of a high incidence compared with that in the general population could not excluded. However, we recently 
Harada et al. - 10 -

encountered an additional 2 cases of MANEC in gallbladder after completing this study (not included herein). Moreover, cases originally diagnosed as a poorly differentiated component (Case 4) or ordinary adenocarcinoma component (Case 2) were included in the biliary MANEC cases found in this study. Therefore, we speculate that biliary MANEC cases are no that rare. Pathologists should take into account the presence of a neuroendocrine component during the pathological diagnosis of biliary cancers.

In the new WHO classification system, neuroendocrine neoplasms in the digestive system are classed as NET G1 including carcinoid tumor, NET G2, and NEC [5]. This classification also applies to biliary neuroendocrine neoplasms [6], but NET G1 was not found in any neuroendocrine components of biliary MANEC morphologically. All neuroendocrine components of biliary MANEC found in this study belonged to NET G2 or NEC. The malignant grade of neuroendocrine neoplasms is generally based on the size of the tumor and cell kinetics (Ki67 labeling index) in addition to tumor morphology [2,3], but there is still no broadly accepted definition of malignant grade in biliary neuroendocrine neoplasms. Because all neuroendocrine components were found in invasive areas of biliary MANEC, it is difficult to define them by the size of a sole neuroendocrine component. However, in this study, neuroendocrine components of biliary MANEC could be classified according to morphology and cell kinetics. That is, NET G2 and NEC show different levels of cell proliferation. Ki67 indices of NEC were constantly higher than those of NET G2 and also those of background adenocarcinoma components. This finding suggests that NET G2 and NEC could be distinguished by morphological atypia and proliferating activity without information on the size of neuroendocrine components in biliary MANEC. It is speculated that biliary tumors containing NEC have a poor prognosis based on histological evaluation. We tried to confirm this using a Kaplan-Maier analysis, but the number of biliary MANECs was too small. Moreover, because the prognosis of biliary tumors appreciably differed with the location in the biliary tree, it was difficult to comprehensively analyze the biliary MANECs found in this study. 
This study revealed that biliary MANECs showed a very characteristic histology, that is, the surface of the tumor was an ordinary adenocarcinoma and the neuroendocrine component was located in an area of vascular and perineural invasion, and lymph node metastasis always involved neuroendocrine components. Moreover, the NEC component showed high proliferative activity, compared with the adenocarcinoma component, suggesting that neuroendocrine components, particularly NEC, in biliary MANEC could prescribe the prognosis. Among the biliary MANECs examined in this study, 2 showed the expression of SSTR2A in NEC, a good indication for the use of somatostatin analogues as adjunctive therapy after surgery.

In this study, $\mathrm{HCC}$, intrahepatic $\mathrm{CC}$, and hepatic hilar $\mathrm{CC}$ without preceding hepatobiliary disease contained no neuroendocrine components, but some cases of hepatic hilar CC with hepatolithiasis, gallbladder cancer, and extrahepatic CC had neuroendocrine components, some of which were a high grade malignancy such as neuroendocrine neoplasm (NEC) and SSTR2A-positive NEC. Pathologists must be aware of the poor prognosis and of cases indicating the need for adjunct therapy including somatostatin analogues after surgical resection.

Conflict of interest statement. The authors have no conflicts of interest to declare. 
Table 1.

Primary antibodies used in this study

\begin{tabular}{|c|c|c|c|}
\hline Antibody & Concentration & Antigen retrieval & Supplier \\
\hline chromogranin A (Ms) & $0.5 \mu \mathrm{g} / \mathrm{ml}$ & no treatment & Dako Japan \\
\hline Synaptophysin (Ms) & $5 \mu \mathrm{g} / \mathrm{ml}$ & MW(citrate buffer) & Dako Japan \\
\hline Ki67 (Ms) & $0.22 \mu \mathrm{g} / \mathrm{ml}$ & MW(EDTA buffer) & Dako Japan \\
\hline SSTR2A (Rb) & diluted 1:1000 & AC(citrate buffer) & Gramsch Laboratories \\
\hline
\end{tabular}

Table 2. Frequency of neuroendocrine cells and neoplasms in hepatobiliary tumors

\begin{tabular}{lcc}
\hline \multirow{2}{*}{ Original diagnosis } & \multicolumn{2}{c}{ Neuroendocrine components } \\
\cline { 2 - 3 } & $\begin{array}{c}\text { neuroendocrine cell } \\
\text { positive / total cases }\end{array}$ & $\begin{array}{c}\text { neuroendocrine neoplasm } \\
\text { positive / total cases }\end{array}$ \\
\hline Intrahepatic CC & $0 / 17(0 \%)$ & $0 / 17(0 \%)$ \\
\hline $\begin{array}{l}\text { hepatic hilar CC without preceding } \\
\text { hepatobiliary diseases }\end{array}$ & $0 / 15(0 \%)$ & $0 / 15(0 \%)$ \\
\hline $\begin{array}{l}\text { hepatic hilar CC associated with } \\
\text { hepatolithiasis }\end{array}$ & $12 / 55(22 \%)$ & $2 / 55(4 \%)$ \\
\hline gallbladder cancer & $19 / 49(39 \%)$ & $5 / 49(10 \%)$ \\
\hline extrahepatic CC & $13 / 53(25 \%)$ & $2 / 53(4 \%)$ \\
\hline hepatocellular carcinoma & $0 / 85(0 \%)$ & $0 / 85(0 \%)$ \\
\hline
\end{tabular}

$\mathrm{CC}$, cholangiocarcinoma. 
Table 3.

Cases of biliary MANEC

\begin{tabular}{|c|c|c|c|c|}
\hline & Case 1 & Case 2 & Case 3 & Case 4 \\
\hline Age, Gender & 60's, Male & 80 's, Female & 70's, Female & 70 's, Female \\
\hline Location & $\begin{array}{c}\text { extrahepatic } \\
\text { bile duct }\end{array}$ & $\begin{array}{l}\text { extrahepatic } \\
\text { bile duct }\end{array}$ & gallbladder & gallbladder \\
\hline precursor lesion & & & cholecystolithiasis & \\
\hline tumor size & $2.2 \times 1.5 \mathrm{~cm}$ & $1.5 \times 1.2$ & $3.5 \times 2.5 \mathrm{~cm}$ & $4.5 \times 1.0 \mathrm{~cm}$ \\
\hline gross classification & mass forming & mass forming & mass forming & mass forming \\
\hline $\begin{array}{l}\text { Histology of } \\
\text { adenocarcinoma }\end{array}$ & pap-wel & wel & wel & pap-wel \\
\hline Histology of NET & NEC, LCNEC & $\begin{array}{c}\text { NET G2, } \\
\text { adenocarcinoma-like }\end{array}$ & $\begin{array}{l}\text { NEC, small cell } \\
\text { carcinoma }\end{array}$ & NEC, LCNEC \\
\hline $\begin{array}{l}\text { Intensity of } \\
\text { neuroendocrine marker }\end{array}$ & + & ++ & ++ & + \\
\hline $\begin{array}{l}\text { Mitotic index of NET } \\
\text { (mitotic count/10 HPF) }\end{array}$ & 53 & 7 & 59 & 137 \\
\hline Ki67 index of NET (\%) & 22.3 & 1.2 & 12.3 & 32.3 \\
\hline $\begin{array}{l}\text { depth of invasion } \\
\text { (histology) }\end{array}$ & $\begin{array}{l}\text { exposure from } \\
\text { serosa (NET) }\end{array}$ & $\begin{array}{l}\text { invasion to pancreas } \\
\text { (NET) }\end{array}$ & $\begin{array}{l}\text { invasion to liver, } \\
\text { (NET) }\end{array}$ & $\begin{array}{l}\text { exposure from } \\
\text { serosa (NET) }\end{array}$ \\
\hline $\begin{array}{l}\text { lymphatic invasion } \\
\text { (histology) }\end{array}$ & $+(\mathrm{NET})$ & $+(\mathrm{NET})$ & $+(\mathrm{NET})$ & $+(\mathrm{NET})$ \\
\hline $\begin{array}{l}\text { vascular invasion } \\
\text { (histology) }\end{array}$ & $+(\mathrm{NET})$ & $+(\mathrm{NET})$ & $+(\mathrm{NET})$ & $+(\mathrm{NET})$ \\
\hline $\begin{array}{l}\text { perineural invasion } \\
\text { (histology) }\end{array}$ & $+(\mathrm{NET})$ & $+(\mathrm{NET})$ & $+(\mathrm{NET})$ & - \\
\hline $\begin{array}{l}\text { lymph node metastasis } \\
\text { (histology) }\end{array}$ & $+(\mathrm{NET})$ & - & $+(\mathrm{NET})$ & - \\
\hline SSTR2A in NET & + & - & - & - \\
\hline
\end{tabular}

pap, papillary adenocarcinoma. wel, well-differentiated adenocarcinoma. LCNEC, large cell neuroendocrine carcinoma. HPF, high powder field. NET G2 and NEC (WHO classification, 2010). 
a sequel of Table 3

\begin{tabular}{|c|c|c|c|c|}
\hline Case 5 & Case 6 & Case 7 & Case 8 & Case 9 \\
\hline 70 's, Female & 60 's, Female & 50 's, Female & 60 's, Male & 70's Female \\
\hline gallbladder & gallbladder & gallbladder & hepatic hilum & hepatic hilum \\
\hline cholecystolithiasis & cholecystolithiasis & & hepatolithiasis & hepatolithiasis \\
\hline $4.5 \times 2.5 \mathrm{~cm}$ & $1.5 \times 1.5 \mathrm{~cm}$ & $15 \times 12 \mathrm{~cm}$ & $>2.5 \mathrm{~cm}$ & $>2.8 \mathrm{~cm}$ \\
\hline mass forming & mass forming & mass forming & mass forming & mass forming \\
\hline wel & pap-wel & wel & wel & wel \\
\hline $\begin{array}{l}\text { NET G2, atypical } \\
\text { carcinoid }\end{array}$ & $\begin{array}{l}\text { NEC, small cell } \\
\text { carcinoma }\end{array}$ & NEC, LCNEC & $\begin{array}{c}\text { NET G2, atypical } \\
\text { carcinoid }\end{array}$ & NEC, LCNEC \\
\hline++ & + & + & + & + \\
\hline 4 & 95 & 42 & 15 & 76 \\
\hline 0.5 & 28.5 & 15.1 & 3.8 & 35.2 \\
\hline $\begin{array}{c}\text { invasion to } \\
\text { duodenum (NET) }\end{array}$ & $\begin{array}{c}\text { subserosa } \\
\text { (adenocarcinoma) }\end{array}$ & $\begin{array}{l}\text { invasion to liver, } \\
\text { (NET) }\end{array}$ & unspecified & unspecified \\
\hline$+(\mathrm{NET})$ & $\begin{array}{c}+(\text { NET and } \\
\text { adenocarcinoma) }\end{array}$ & $+(\mathrm{NET})$ & $+(\mathrm{NET})$ & $+(\mathrm{NET})$ \\
\hline- & $\begin{array}{c}+(\text { NET and } \\
\text { adenocarcinoma) }\end{array}$ & $+(\mathrm{NET})$ & - & - \\
\hline$+(\mathrm{NET})$ & $+(\mathrm{NET})$ & $+(\mathrm{NET})$ & - & - \\
\hline- & $\begin{array}{c}+(\text { NET and } \\
\text { adenocarcinoma })\end{array}$ & $+(\mathrm{NET})$ & unspecified & unspecified \\
\hline- & - & + & - & - \\
\hline
\end{tabular}




\section{REFERENCES}

1. Capella C, Solcia E, Sobin L, Arnold R: Endocrine tumors of the gallbladder and extrahepatic bile ducts. In: Hamilton S, Aaltonen L, eds. WHO classification of tumors of the digestive system; World Health Organization of Tumors. Lyon: IARC Press, 2000; 214-216.

2. Kloppel G, Perren A, Heitz PU (2004) The gastroenteropancreatic neuroendocrine cell system and its tumors: the WHO classification. Ann N Y Acad Sci 1014: 13-27.

3. Kloppel G (2007) Tumour biology and histopathology of neuroendocrine tumours. Best Pract Res Clin Endocrinol Metab 21: 15-31.

4. Rindi G, Kloppel G, Alhman H, et al. (2006) TNM staging of foregut (neuro)endocrine tumors: a consensus proposal including a grading system. Virchows Arch 449: 395-401.

5. Rindi G, Klimstra DS, Arnold R, et al.: Nomenclature and classification of neuroendocrine neoplasms of the digestive system. In: Bosman FT, Carneiro F, Hruban RH, Theise ND, eds. WHO classification of tumors of the digestive system; World Health Organization of Tumors. 4th ed. Lyon: IARC, 2010; 13-14.

6. Komminoth P, Arnold R, Capella C, et al.: Neuroendocrine neoplasms of the gallbladder and extrahepatic bile ducts. In: Bosman FT, Carneiro F, Hruban RH, Theise ND, eds. WHO classification of tumors of the digestive system; World Health Organization of Tumors. 4th ed. Lyon: IARC, 2010; 274-276.

7. Volante M, Brizzi MP, Faggiano A, et al. (2007) Somatostatin receptor type 2A immunohistochemistry in neuroendocrine tumors: a proposal of scoring system correlated with somatostatin receptor scintigraphy. Mod Pathol 20: 1172-1182.

8. Oberg KE, Reubi JC, Kwekkeboom DJ, Krenning EP (2010) Role of somatostatins in gastroenteropancreatic neuroendocrine tumor development and therapy. Gastroenterology 139: $742-753,753$ e 741 .

9. Kurumaya H, Ohta G, Nakanuma Y (1989) Endocrine cells in the intrahepatic biliary tree in normal livers and hepatolithiasis. Arch Pathol Lab Med 113: 143-147.

10. Tsuchiya A, Endo Y, Yazawa T, et al. (2006) Adenoendocrine cell carcinoma of the gallbladder: report of a case. Surg Today 36: 849-852.

11. Nesi G, Lombardi A, Batignani G, et al. (2006) Well-differentiated endocrine tumor of the distal common bile duct: a case study and literature review. Virchows Arch 449: 104-111.

12. Squillaci S, Marchione R, Piccolomini M, et al. (2010) Well-differentiated neuroendocrine carcinoma (malignant carcinoid) of the extrahepatic biliary tract: report of two cases and literature review. Apmis 118: 543-556.

13. Shimizu T, Tajiri T, Akimaru K, et al. (2006) Combined neuroendocrine cell carcinoma and adenocarcinoma of the gallbladder: report of a case. J Nippon Med Sch 73: 101-105. 
Harada et al. - 16 -

14. Kuraoka K, Taniyama K, Fujitaka T, et al. (2003) Small cell carcinoma of the extrahepatic bile duct: case report and immunohistochemical analysis. Pathol Int 53: 887-891.

15. Kozaka K, Fujii T, Harada K, et al. (2007) A subgroup of intrahepatic cholangiocarcinoma with an infiltrating replacement growth pattern and a resemblance to reactive proliferating bile ductules: 'bile ductular carcinoma'. Histopathology 51: 390-400. 
Harada et al. - 17 -

\section{FIGURE LEGENDS}

Fig.1 Immunohistochemistry for chromogranin A. Chromogranin A-immunoreactive neuroendocrine cells are scattered in non-neoplastic biliary epithelium of gallbladder cancer (A) and adenocarcinoma of extrahepatic cholangiocarcinoma (B). Some neuroendocrine cells resembling enterochromaffin-like cells morphology which show a triangular shape and are located in the basement membrane, are also found (arrow). Original magnification, x200.

Fig.2 Gallbladder cancer with neuroendocrine tumor (NET) G2 (WHO classification, 2010) (Case 5 in Table 3). Although the surface of the tumor is an ordinary adenocarcinoma (A, arrow) (higher magnification, D), the invasive component shows a different histology and chromogranin A-positivity (A and $\mathrm{B}, *$ ). Tumors show a trabecular pattern and consist of small monotonous cells with mild atypia, indicating atypical carcinoid (C). (A), (B), and (D) are H\&E staining. (B) immunohistochemistry for chromogranin A. Original magnification, (A) and (B), x20; (C), x200; and (D), x100.

Fig.3 Gallbladder cancer with neuroendocrine carcinoma (NEC) (WHO classification, 2010) (Case 6 in Table 3). A solid component is found within the adenocarcinoma area $(\mathrm{A}, *)$. The solid part consists of intermediate-sized round cells with nuclear molding and scanty cytoplasm resembling small cell carcinoma of the lung (B). Several mitoses (arrowheads) and necrosis (N) are found (B). Original magnification, (A), x20; (B), x400.

Fig.4 Hepatic hilar cholangiocarcinoma associated with hepatolithiasis accompanying neuroendocrine carcinoma (NEC) (WHO classification, 2010) (Case 9 in Table 3). An ordinary adenocarcinoma (A, arrow) is found in the lumen of a hepatic hilar bile duct, but the 
proliferating invasive nest shows solid sheets $\left(\mathrm{A},{ }^{*}\right)$. The latter part consists of uniform and large-sized tumor cells resembling large cell neuroendocrine carcinoma of the lung (B). Arrowheads denote mitoses. Original magnification, (A), x20; (B), x400.

Fig.5 Extrahepatic cholangiocarcinoma with neuroendocrine tumor (NET) G2 (WHO classification, 2010) showing adenocarcinoma morphology (Case 2 in Table 3). The tumor is histologically an ordinary adenocarcinoma (A and C), but diffusely positive for chromogranin A except at the surface (B). (A) and (C) H\&E staining. (B) Immunohistochemistry for chromogranin A. Original magnification, (A) and (B), x20; (C), x200.

Fig.6 Comparative analysis of cell kinetics between adenocarcinomas and neuroendocrine neoplasms. Many Ki-67-positive cells are found within neuroendocrine carcinoma (NEC, large cell neuroendocrine carcinoma type)(WHO classification, 2010) (A, arrow, and B), but rarely in adenocarcinomas (A, upper left). In two cases of neuroendocrine tumor (NET) G2 (WHO classification, 2010), there is no significant difference in the percentage of Ki67-positive cells (Ki67 index) between adenocarcinoma and NET G2, but in other all cases, particularly NEC, the indices are increased in neuroendocrine components (C). Immunohistochemistry for Ki67 (A and B). Original magnification, (A), x20; (B), x100.

Fig.7 Somatostatin receptor 2A (SSTR2A)-positive case (Case 1 in Table 3). An intense membranous pattern is found in tumor cells (large cell neuroendocrine carcinoma type). Immunohistochemistry for SSTR2A. Original magnification, $\mathrm{x} 400$. 


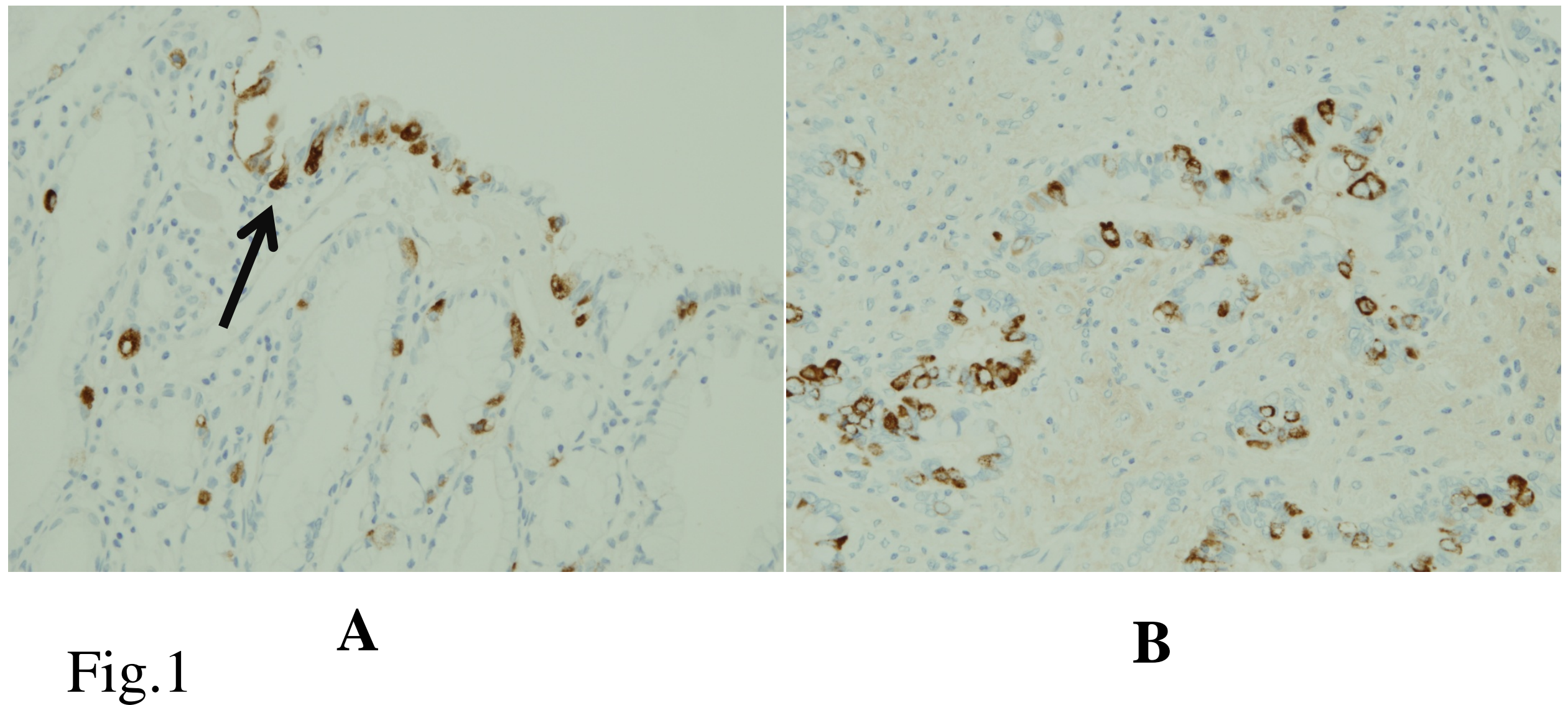


A
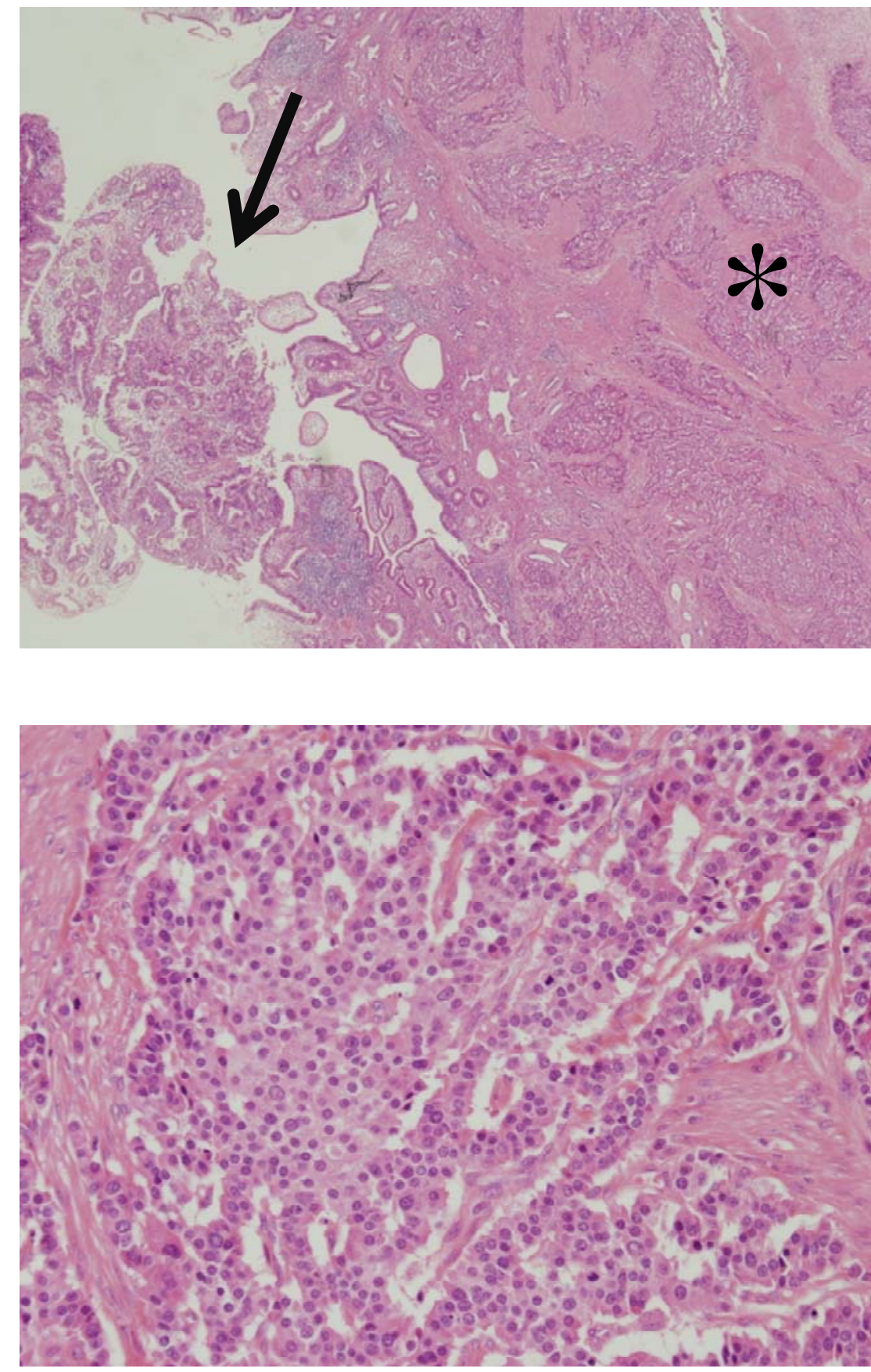

B

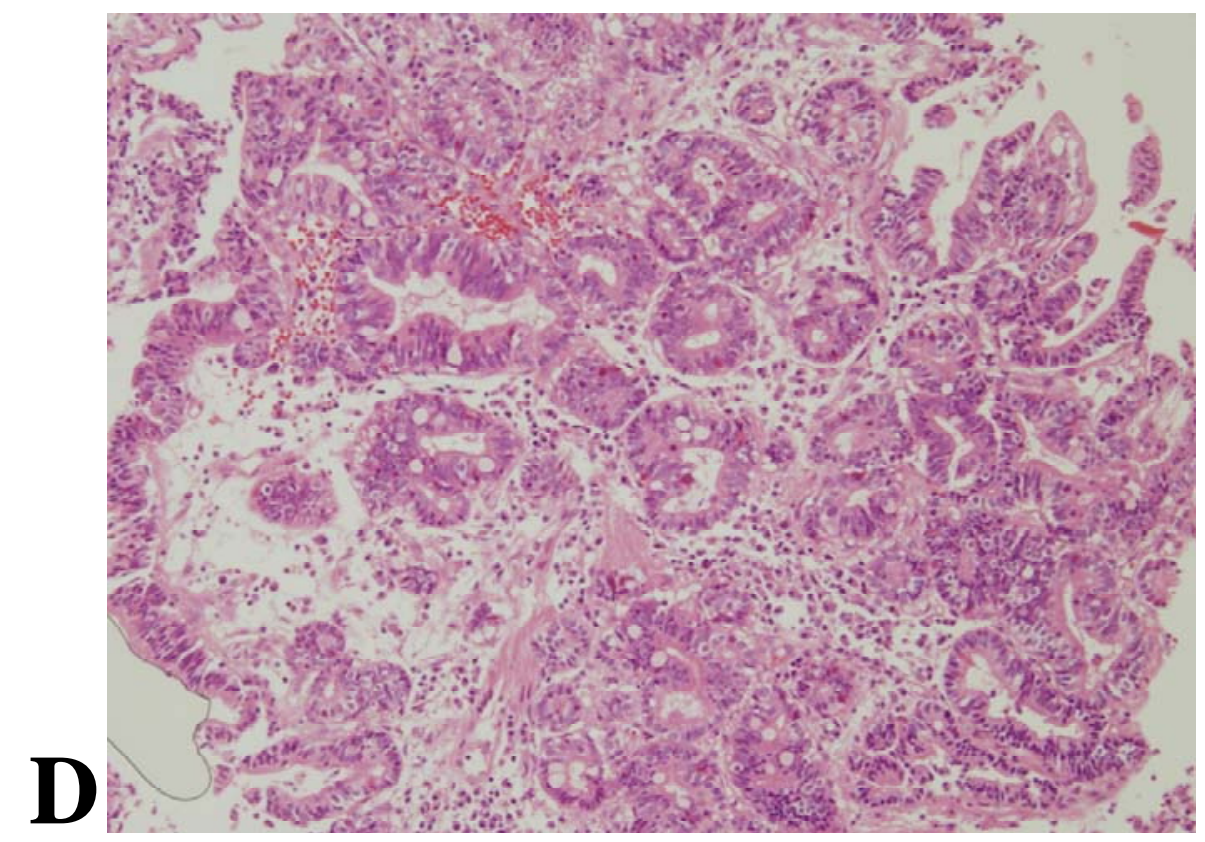

Fig.2 

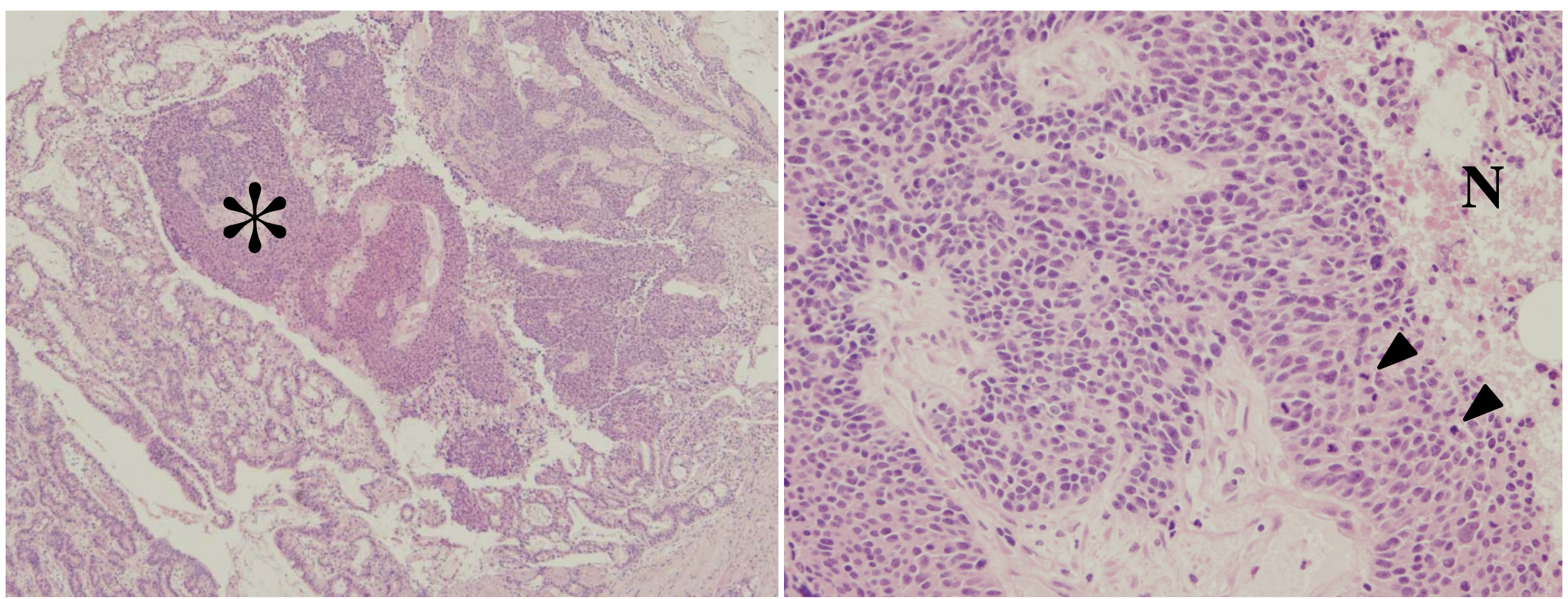

A

B

Fig.3 


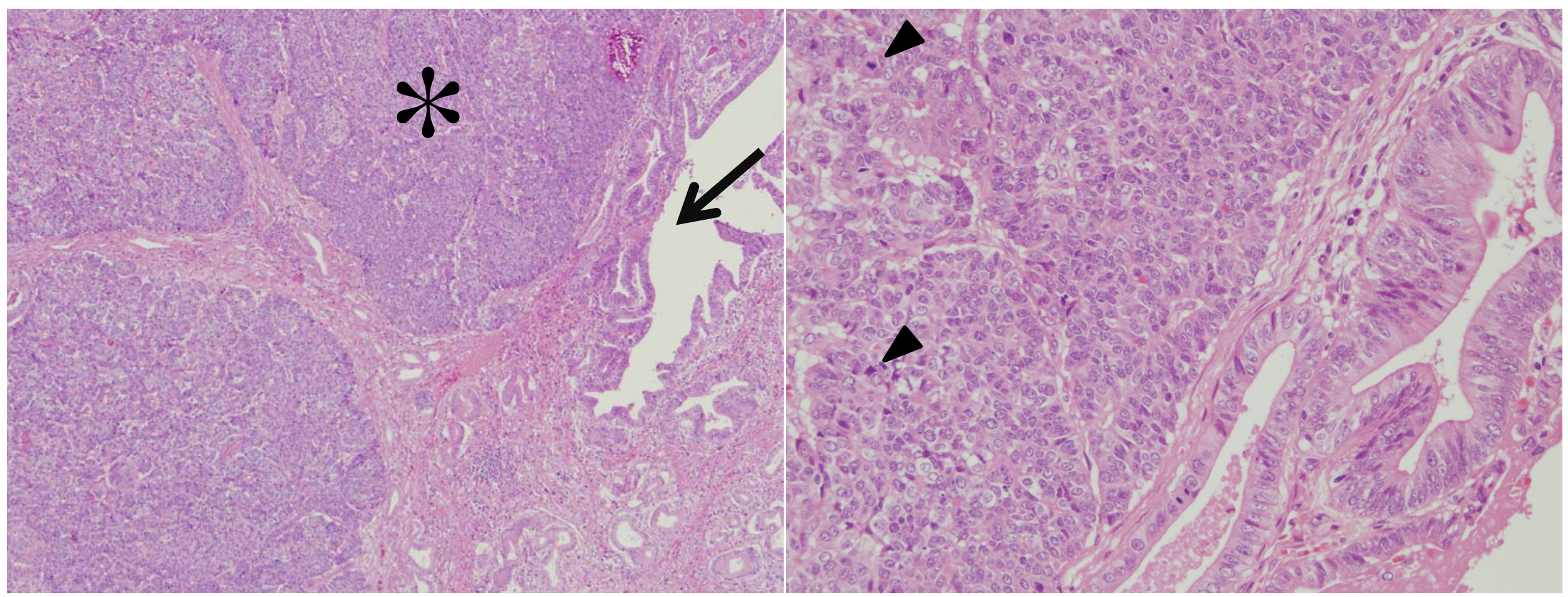

A

B

Fig.4 

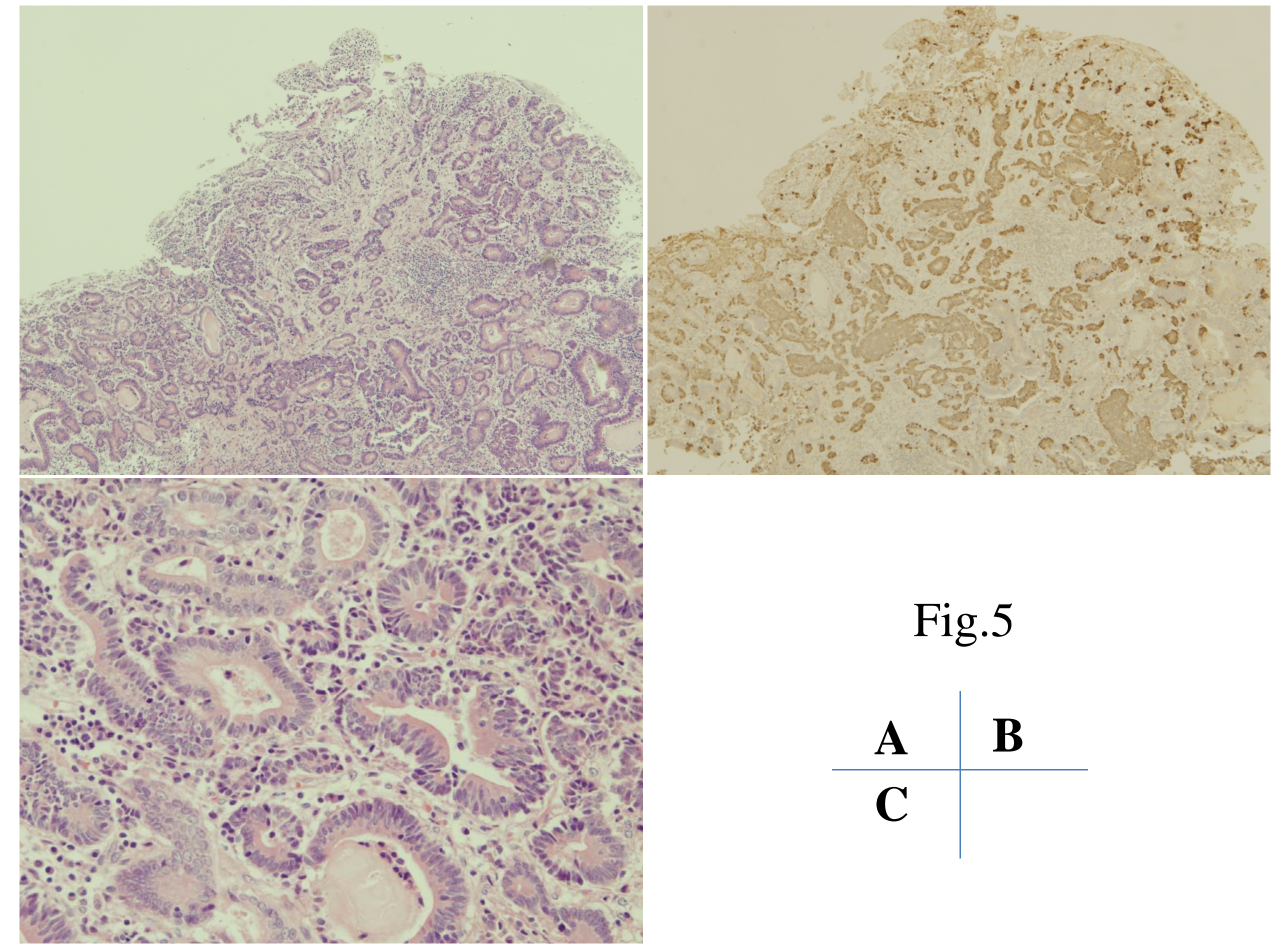

Fig.5 


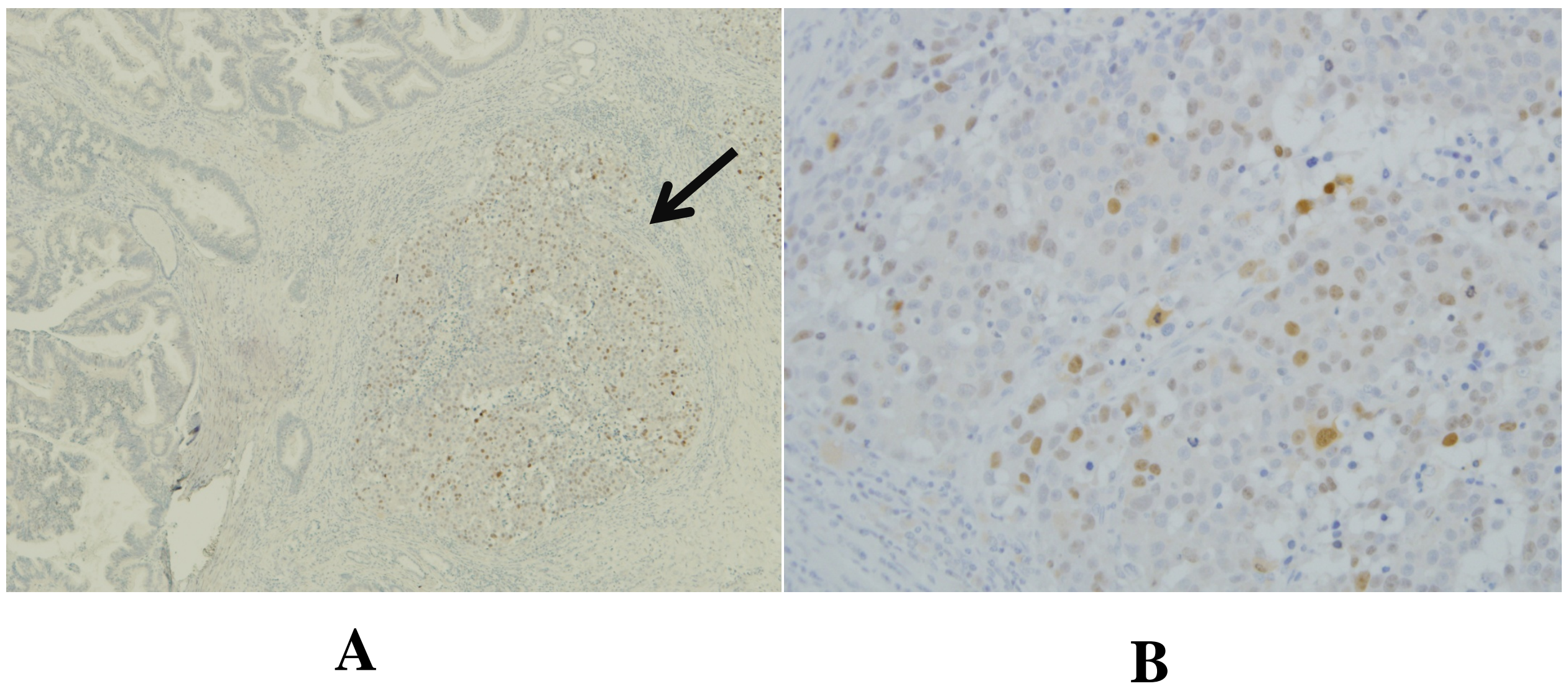

Fig.6A,B 
Fig.6C

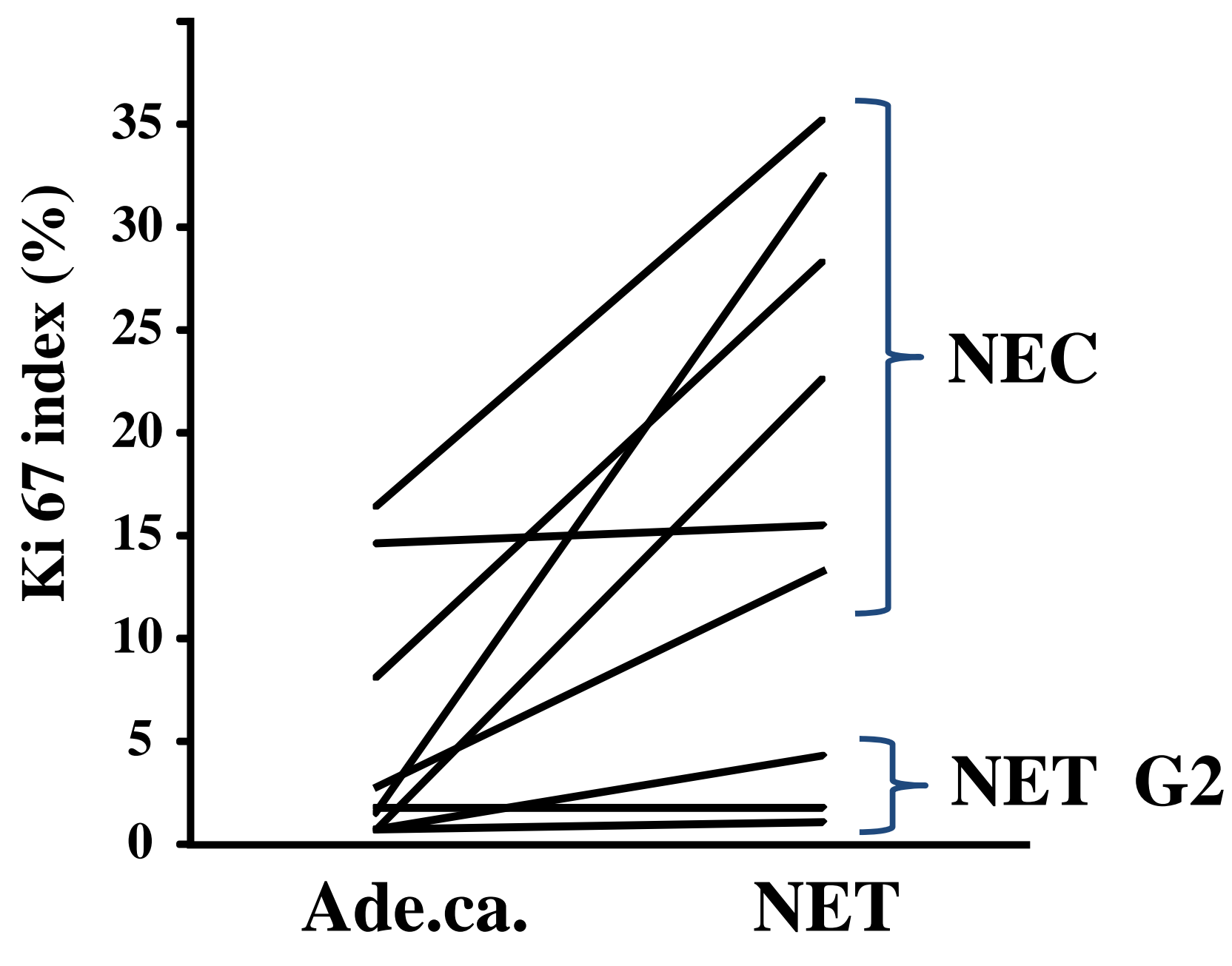




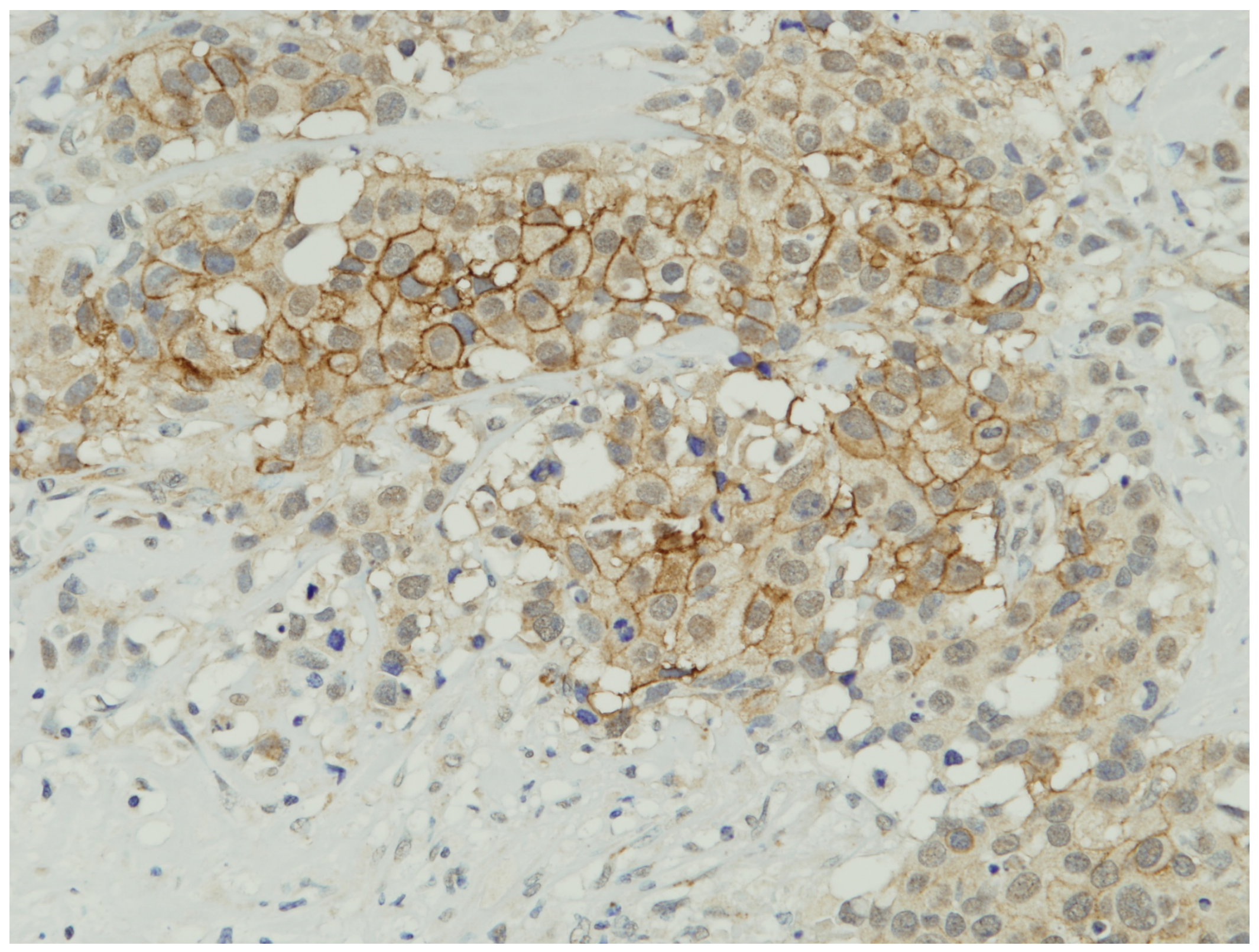

Fig.7 